\title{
Negligent exposures to hand-transmitted vibration
}

\author{
MICHAEL J. GRIFFIN
}

\author{
Michael J Griffin $\bowtie$ \\ Human Factors Research Unit \\ Institute of Sound and Vibration Research \\ University of Southampton \\ Southampton SO17 1BJ \\ Telephone: (+44) 02380592853 \\ Facsimile: (+44) 02380592927 \\ e-mail: M.J.Griffin@soton.ac.uk
}

Work presented at the 2nd International Workshop 2006 on Diagnosis of Hand-Arm Vibration Syndrome in Göteborg, Sweden. 


\begin{abstract}
Objectives: If the negligence of an employer results in the disability in an employee, the employer is responsible, in whole or in part, for the disability. The employer is wholly responsible when the worker would not have developed the disability if the employer had taken all reasonable preventative measures. The employer is only partly responsible if the worker would probably have developed some disability even if the employer had taken all reasonable precautions. The employer's responsibility may be estimated from the difference between the actual disability of the worker and the disability that the worker would have suffered if the employer had taken all reasonable preventative measures. This paper considers alternative ways of apportioning negligent and non-negligent exposures to hand-transmitted vibration.

Results: The equivalent daily vibration exposure, $A(8)$, used in current EU Directives is shown to be unsuitable for distinguishing between the consequences of negligent and non-negligent exposures because the risks of developing a disorder from hand-transmitted vibration also depend on the years of exposure. Furthermore, daily exposures take no account of individual susceptibility or the practicality of reducing exposure. The consequences of employer negligence may be estimated from the delay in the onset and progression of disorder that would have been achieved if the employer had acted reasonably, such as by reducing vibration magnitude and exposure duration to the minimum that was reasonably achievable in the circumstances. This seems to be fair and reasonable for both employers and employees and indicates the consequences of negligence - the period of the worker's life with disease as a result of negligence and the period for which their employment opportunities may be restricted as a result of the onset of the disorder due to negligence.
\end{abstract}

Conclusions: The effects of negligence may be estimated from the delay in the onset of disease or disability that would have occurred if the employer had behaved reasonably. This definition of negligence encourages employers to reduce risks to the lowest reasonably practical level, consistent with EU Directives.

Key words Hand-transmitted vibration, vibration-induced white finger, hand-arm vibration syndrome, symptoms, signs. 


\section{INTRODUCTION}

Negligence occurs when individuals or organisations fail to do something they should have done, such as failing to provide care for those they are responsible for. Workers exposed to handtransmitted vibration are at risk of developing various disorders collectively known as the hand-arm vibration syndrome [9]. Employers who fail to take reasonable steps to minimise the risks may be considered negligent. This paper considers what is negligent and how to anticipate the consequences of negligent exposures.

Ideally, all risks from hand-transmitted vibration would be eliminated. There is no known safe exposure to hand-transmitted vibration, so the elimination of all risks is only possible if all work involving hand-transmitted vibration is eliminated, either by introducing machinery that eliminates human contact with vibration or by eliminating the need for work involving hand-transmitted vibration. Where a job requires exposure to hand-transmitted vibration, the risks can be reduced by reductions in vibration magnitude (by tool selection and maintenance, and tool operation), by reductions in exposure duration (by rotation of work or the imposition of exposure limits), and by other methods.

Employers of persons who develop disorders may not be considered negligent if they could not have known that a disorder would ensue, or if they were incapable of preventing the disorder without taking unreasonable precautions. Where an employer should have anticipated a risk and failed to take reasonable measures that would have reduced the risks, the employer can be considered negligent. However, employers may argue that they are only responsible for the difference between what did happen to the worker and what would have happened if they had taken all reasonable measures to minimise the risks to the worker.

Employers need to know the consequences of their actions and inactions in order to decide what actions to take. At one level, employers need to know the likely benefit of reducing vibration exposure (both vibration magnitude and exposure duration). At another level, employers need to know whether society (e.g. the courts) will hold them fully responsible for any disease that develops while a worker is in their employment or whether they will only be considered responsible for that portion of the disease that arose from exposures they could have prevented by reasonable actions. Prospective employers can only assess the risks to them when employing a person who will be exposed to vibration if they assume a relationship between vibration exposure and the development of disease. Although there are standards and guides offering relationships between vibration exposure and disease they have not been developed for this purpose, and there are several alternative ways of apportioning the responsibility of employers.

The problem is similar to the apportionment of responsibility for the development of a chronic disorder in a worker when some past exposure with another employer may have already contributed some damage, even without symptoms, in the worker. Should the employer who 
employs a person who may already be damaged by vibration be held responsible for the entire damage when it subsequently appears? If not, how should the damage be apportioned between employers?

The two apportionment problems are not merely considerations that decide responsibility for what has happened. Both can affect decisions on whether to employ a worker, whether to continue to employ a worker, and what precautions to take when exposing workers to hand-transmitted vibration.

This paper considers alternative procedures for allowing for non-negligent exposures to handtransmitted vibration. The validity of alternative methods, their assumptions, and consequences, their ease of application and whether they merely define negligence or give a useful indication of the consequences of negligence are considered. It is recognised that worker compensation differs between countries, with no compensation in some countries and payment irrespective of employer negligence in others. It may nevertheless be helpful to evolve an appropriate definition of negligence since the reduction of negligence should reduce the harmful effects of hand-transmitted vibration irrespective of worker compensation.

\section{THE BACKGROUND}

Various standards, guides and research reports suggest how the consequences of exposures to hand-transmitted vibration depend on the magnitude of vibration and the duration of exposure. Some of these documents have been produced with the express purpose of influencing employers to take precautions to reduce the risks from hand-transmitted vibration. However, the science underpinning current understanding of the factors influencing the development of disorders caused by hand-transmitted vibration is weak $[4,5,7]$.

The knowledge to be expected of the employer of a worker who has been exposed to handtransmitted vibration over recent years is summarised in various standards (e.g. [2, 10, 11]). Current standards give methods of measuring and evaluating the vibration magnitude on powered hand tools and also contain dose-response guidance (e.g. an annex to ISO 5349 (1986) and an appendix to BS 6842 (1987)). The standards give information on the relative importance of vibration magnitude, vibration frequency, daily exposure duration, and lifetime exposure duration that are thought to influence the development of vibration-induced white finger. There is currently no guidance on the likely incidence of non-vascular disorders or the disability arising from either vascular or non-vascular disorders.

In an informative annex of ISO 5349-1 (2001) there is a suggested relation between the lifetime exposure to hand-transmitted vibration, $y_{10 \%}$, (in years) and the 8-hour energy-equivalent daily exposure $A(8)$ for the conditions expected to cause $10 \%$ prevalence of finger blanching (Figure 1 ):

$$
y_{10 \%}=31.8[A(8)]^{-1.06} .
$$




\section{FIGURE 1 ABOUT HERE}

The percentage of affected persons in any group of exposed persons will not always correspond to the values shown in Figure 1: the frequency weighting, the time-dependency and the dose-effect information are based on less than complete information and they have been simplified for practical convenience [6, 7]. Additionally, the number of persons affected by vibration will depend on the rate at which persons enter and leave the exposed group. The complexity of the above equation implies far greater precision than is possible: a more reasonable and convenient estimate of the years of exposure (in the range 1 to 25 years) required for $10 \%$ incidence of finger blanching is:

$$
y_{10 \%} \approx \frac{30}{A(8)}
$$

This equation gives the same result as the equation in the standard (to within 14\%) and there is no information suggesting it is less accurate. Although it is widely believed that ISO 5349 (2001) is not accurate, changes are not likely until evidence provides a more complete scientific basis for the relation between finger blanching (and other disorders), vibration magnitude, vibration frequency, daily exposure duration and lifetime exposure duration.

International Standard 5349 (2001) says that the probability of individuals developing symptoms of the hand-arm vibration syndrome depends on their susceptibility, any pre-existing diseases and conditions, and various work-related, environmental and personal factors. Consequently, while the dose-response relationship in the standard is assumed to apply to a group of persons who are similarly exposed, it is not offered to predict the risk of finger blanching (i.e. vibration-induced white finger) in any particular individual within the group. Epidemiological studies consistently show a very large variability in susceptibility to injury between individuals: one worker may develop symptoms after one year while others who are similarly exposed may have no symptoms after 30 years.

Because International Standard 5349 (2001) will sometimes greatly over-estimate the risks and sometimes greatly under-estimate the risks, better guidance may come from knowledge of the risks associated with a particular type of work. For example, the history of disease occurring with a type of tool or job may be used to anticipate future risk in a group of exposed persons. Similarly, knowledge of what tool use has caused injury in an individual may be used to estimate the effects of changes in tool use for that individual. This may be estimated for changes that could have been made in the past and for changes that can be made in the future.

The current EU Physical Agents Directive defines an 8-hour equivalent 'exposure action value' of $2.5 \mathrm{~ms}^{-2}$ r.m.s. and an 8-hour equivalent 'exposure limit value' of $5.0 \mathrm{~ms}^{-2}$ r.m.s. [12]. The Directive says workers shall not be exposed above the 'exposure limit value'. If the 'exposure action values' are exceeded, the employer shall establish and implement a programme of technical and/or organisational measures intended to reduce to a minimum exposure to mechanical vibration and 
the attendant risks. The Directive requires that workers exposed to mechanical vibration in excess of the exposure action values shall be entitled to appropriate health surveillance. However, health surveillance is not restricted to situations where the exposure action value is exceeded: health surveillance is required if there is any reason to suspect that workers may be injured by the vibration, even if the action value is not exceeded.

According to ISO 5349-1 (2001), the onset of finger blanching would be expected in $10 \%$ of persons after 12 years at the EU 'exposure action value' and after 5.8 years at the 'exposure limit value'. Clearly, the 'exposure action value' and the 'exposure limit value' in the Directive do not define 'safe exposures' to hand-transmitted vibration. Consequently, it does not seem reasonable to conclude that an employer fulfils all obligations to an employee in respect of exposures to handtransmitted vibration if the EU 'exposure action value' is not exceeded. As discussed below, negligence cannot be determined directly from either the current International Standard or the current European Directive for hand-transmitted vibration.

\section{APPORTIONING NEGLIGENCE}

It will be assumed that a fair apportionment of an employer's responsibilities can be based on a few simple principles.

Assuming that exposures to hand-transmitted vibration prior to some date (e.g. possibly $1^{\text {st }}$ January 1976 in the UK) are non-negligent due to lack of knowledge of the consequences, and that a worker was asymptomatic on that date:

(i) An employer is wholly responsible for any subsequent disability when, on the balance of probabilities, a worker would not have subsequently developed a significant disability if the employer had taken all reasonable preventative measures;

(ii) The employer's responsibility can be apportioned if the worker would probably have developed a disability even if the employer had taken all reasonable precautions. The extent of the apportionment should be based on the difference between the actual disability of the worker and the disability that the worker would have suffered if the employer had taken all reasonable preventative measures.

It is helpful to consider the negligence of an employer in controlling risks in two parts:

(i) the extent to which exposures to hand-transmitted vibration were negligent and the effects of this negligence on the employee's current and future health (this requires a quantification of both the negligent and the non-negligent exposures, taking into account the vibration magnitudes and the exposure durations);

(ii) the extent to which the employer was negligent in respect of other factors (e.g. the provision of warning, education, training, health surveillance) and the effects of any such negligence on the employee's current and future health. This may be difficult to achieve in any quantitative manner and may sometimes be a qualitative assessment by a court and is mainly outside the scope of the current paper. 
The apportionment between negligent and non-negligent exposures assumes that it is understood: (a) what did happen as a result of the employee's actual exposure to hand-transmitted vibration, and (b) what would have happened if the employee had been exposed to the greatest 'nonnegligent exposure'. A similar approach can be used when considering the impact of the other factors that an employer can take in respect of warning, education, training, and health surveillance.

\section{ALTERNATIVE METHODS OF QUANTIFYING NEGLIGENCE}

A satisfactory method of defining negligence will inform and guide employers and also provide a basis for assessing how compensation for the disability arising from exposures to hand-transmitted vibration should be adjusted to take account of what would have happened if the employer had not been negligent.

\subsection{Method A: negligence based on severity of disease}

Negligence could be quantified solely on the disability of the employee, without considering the employee's exposure to hand-transmitted vibration, other than to confirm that the disability is probably vibration-induced. An employer might be considered fully responsible for the difference between the disability suffered by an employee and an 'acceptable level of disability' that the employee could be permitted without the employer being considered negligent.

With current practice, the disability of an employee is only roughly reflected in the widely used methods of staging the hand-arm vibration syndrome (the Stockholm vascular scale and the Stockholm sensorineural stage [1, 3]), and other methods may be appropriate [8]. If it were concluded that suitable precautionary measures (especially health surveillance) could have restricted the disease to a lower stage on an appropriate scale, the apportionment of responsibility would be based on the difference between a compensation award appropriate to the higher stage (as experienced by the employee) and an award appropriate to the lower stage (to which the disease should have been restricted).

The method becomes simple if it is assumed that employers should prevent the progression beyond the first stage of disease for which any compensation is applicable. As an example, if stage $N$ were considered to present an acceptable degree of disability, at which no compensation was payable, compensation would be applicable for any progression beyond stage $N$. In other words it is not negligent to allow an employee to develop stage $N$ symptoms but the employer is fully responsible for any progression of disease beyond stage $N$.

The method is simple and has advantages over some of the other methods described below. It takes into account human variability in susceptibility to disease and the progression of disease. It does not require vibration measurements, calculations of exposure durations, dose calculations, or arguments over alternative measurements and calculations. However, it implies that it is not negligent to allow 
workers to develop disease, even if the onset of disease could have been prevented, and it does not directly encourage reductions in vibration exposure.

This is the simplest method considered here but it has significant limitations (see Table 1). This method of apportionment could be combined with other methods that identify negligent exposures, leaving Method $A$ to identify any additional negligence for allowing the disease to progress beyond stage $N$.

\section{TABLE 1 ABOUT HERE}

\subsection{Method B: negligence based on a daily exposure action value}

An employer could be held responsible only for exposures in excess of an 'action level' emanating from the responsible government at the time of the exposures (e.g. the EU 'exposure action value'). The employer is then liable for a measure of 'lifetime dose' assumed to have been received by the worker, less the life-time dose that would have been received if the worker had been exposed for the same number of years at the appropriate daily action value. The percentage responsibility for the employer's negligence might be determined from the difference between the actual lifetime dose and the life-time dose that would have been received if the employee had been exposed at the daily action level, expressed as a percentage of the employee's actual lifetime dose. The measure of dose may not have a simple relation to disability, so negligence would be better based on the predicted different effects of the reduced dose and the actual dose.

Common lifetime exposures to hand-transmitted vibration at the current EU exposure action value can present a significant risk of finger blanching. Furthermore, recognising that past guidance is relevant when considering past exposures, according to the formulae in ISO 5349 (1986), more than $50 \%$ would be affected after 20 years exposure at the EU $2.5 \mathrm{~ms}^{-2}$ r.m.s. exposure action value. Similar to a list of tools and processes likely to create hazardous vibration, 'action values' can be likened to a flag raised to warn of a possible risk. Daily action values do not depend on the number of years of exposure, and were not designed to predict the extent of any risk. This, and other uncertainties, means that some exposures in excess of the action level are not likely to cause detectable injury while others below the action level are likely to cause injury. The action value should not be used as a target because it will not eliminate risk - it is merely one of several possible triggers for raising the caution flag and identifying a possible risk. If a limiting daily $A(8)$ were to be used to define negligence it would need to be based on an $A(8)$ much lower than 2.5 $\mathrm{ms}^{-2}$ r.m.s. In International Standard 5349-1 (2001), there is a footnote stating: "Studies suggest that symptoms of the hand-arm vibration syndrome are rare in persons exposed with an 8-h energy-equivalent vibration total value, $A(8)$, at a surface in contact with the hand, of less than 2 $\mathrm{m} / \mathrm{s}^{2}$ and unreported for $A(8)$ values of less than $1 \mathrm{~m} / \mathrm{s}^{2}$ ". An $A(8)$ of $1.0 \mathrm{~ms}^{-2}$ r.m.s. is predicted to result in $10 \%$ incidence of finger blanching after 31.8 years according to ISO 5349 (2001) (see Figure 1). 
If the average daily exposure is at an exposure action value, about $50 \%$ of daily exposures will be in excess of the action value. If the action value is not to be exceeded on individual days, the average daily exposure will need to be well below the daily exposure action value.

A daily action value cannot predict a chronic disorder that depends on the years of exposure: a few years at the action level may carry a low risk while many years may present a high risk. Employers should expect that the risk of injury will increase with increasing years of exposure to handtransmitted vibration.

There are very many problems with this method (see Table 2). A daily exposure action value is not directly related to harm, symptoms or disability and it does not take into account individual variability in susceptibility. The epidemiological evidence on which the standards (and therefore the action value) are based is not strong, but clearly suggests that persons exposed at the action value over a long period can be at high risk of injury. Inaccuracies in the method of predicting risk (the frequency weighting and the time-dependencies) mean an action value will over-estimate or underestimate risk - whereas knowledge of the risks associated with specific tools and jobs can be a better means of estimating risk.

\section{TABLE 2 ABOUT HERE}

\subsection{Method C: negligence based on exposures expected to produce $10 \%$ finger blanching.}

This method is an extension to Method $B$, but based on a lifetime exposure.

From ISO 5349 (2001), an exposure of $t$ hours to a frequency-weighted acceleration of $a_{\mathrm{hw}}$ is equivalent to an 8-hour exposure, $A(8)$, when:

$$
A(8) \approx a_{\mathrm{hw}} \sqrt{\frac{t}{T_{(8)}}}
$$

where $T_{(8)}$ is 8 hours.

From equations (ii) and (iii) it follows that for an acceleration $a_{\mathrm{hw}}\left(\mathrm{ms}^{-2}\right.$ r.m.s.) with a daily exposure duration of $t$ (hours), the years of exposure, $y_{10} \%$, before $10 \%$ develop finger blanching is given by:

$$
y_{10 \%}=\frac{30 \cdot \sqrt{T_{(8)}}}{a_{h w} \cdot \sqrt{t}}
$$

A simple lifetime measure of dose, $d$, might be defined to maintain the same relationships between vibration magnitude, daily and lifetime exposure:

$$
d=a_{\mathrm{hw}} \cdot y \cdot \sqrt{ } t
$$

This measure of dose may be expressed in terms of the equivalent daily acceleration, $A(8)$ :

$$
d=A(8) \cdot y \cdot \sqrt{ } T_{(8)}
$$


From equations (ii) and (vi), a 10\% incidence of finger blanching would be expected with a dose, $d_{10 \%}$, if:

$$
d_{10 \%}=30 \cdot \sqrt{ } 8 \approx 85 \mathrm{~ms}^{-2} \cdot \mathrm{y} \cdot \mathrm{s}^{1 / 2}
$$

With the above values, this method is equivalent to saying that a dose corresponding to $10 \%$ finger blanching is acceptable (i.e. not negligent). This dose could be discounted from the total dose experienced by a worker when deciding what portion of the worker's exposure is negligent.

With this method, the limiting daily exposure reduces with increasing years of 'expected exposure' to hand-transmitted vibration. The daily exposures would be less than the EU $2.5 \mathrm{~ms}^{-2}$ r.m.s. exposure action value for those exposed (in past, current or future employment) for more than 12 years. Conversely, levels in excess of the action value might be considered non-negligent if a worker was exposed for less than 12 years.

This method reduces some of the limitations of Method B but significant limitations remain (see Table 3).

\section{TABLE 3 ABOUT HERE}

The dose measure defined above means that the vibration magnitude (and daily $A(8)$ ) would need to halve for every doubling of the years of exposure, so while an $A(8)$ of $2.5 \mathrm{~ms}^{-2}$ r.m.s. may be appropriate for 12 years of exposure, the $A(8)$ would be only $1.25 \mathrm{~ms}^{-2}$ r.m.s. for 24 years of exposure, and even lower for longer exposures. These will not always be reasonably achievable.

\subsection{Method D: negligent exposure based on limiting exposures to an action value and to conditions not expected to produce $10 \%$ finger blanching}

This method is a combination of Methods B and C: all exposures which are either in excess of the relevant action level or likely to give rise to, say, $10 \%$ incidence of finger blanching are considered negligent. This method implies that exceeding either boundary in Figure 1 would be considered a negligent exposure.

This combination of methods reduces the limitations of both Method B and Method C but some important limitations remain (see Table 4). Above all, the method does not take into account individual variability in the development and progression of disorders caused by hand-transmitted vibration. The use of the two different methods would also make it difficult to apportion responsibility when more than one employer is involved.

\section{TABLE 4 ABOUT HERE}

A series of employers could expose a worker to a dose just short of the negligent dose, with the cumulative exposure likely to result in finger blanching. However, this is a less serious problem than with method $\mathrm{C}$ because it will only arise with periods of employment greater than 12 years (if 
using the dose $10 \%$ criterion and current standards): for shorter periods, the exposures are limited by the action value.

\subsection{Method E: negligent exposure based on reasonably achievable vibration magnitudes and daily exposure durations}

Methods $B$ to $D$ use guidance from standards and the EU exposure action value to define negligent exposures. Employers may argue that reducing vibration exposures to these levels is not always reasonably practical or, conversely, an employee might argue that lower exposures were reasonably practical.

Method $E$ is based on what is considered reasonably practical. It will be assumed that suitably informed and balanced experts will decide the minimum vibration exposure that could have been achieved for an employee if the employer had taken all reasonable preventative measures. The percentage responsibility for the employer's negligence is determined from the difference between the employee's actual exposure (which also has to be agreed by the experts) and the minimum achievable vibration exposure, expressed as a percentage of the employee's actual exposure. The vibration exposures might be expressed in some form of dose measure (see above).

The method does not take into account individual variability in the development and progression of disorders caused by hand-transmitted vibration and there are various other problems (see Table $5)$.

\section{TABLE 5 ABOUT HERE}

Although this method seems logical it may be difficult to apply in practice, mainly due to the differing opinions on the actual and the reasonably achievable exposures - absolute magnitudes and absolute durations are required for both.

\subsection{Method F: negligent exposure based on percentage of days on which an action value is exceeded}

Negligent exposure could be said to occur on any day when an exposure action value is exceeded. With this approach, an apportionment might be based on the proportion (i.e. percentage) of working days on which an action value was likely to have been reached or exceeded.

In this method, it is assumed that the employer is negligent on every day on which the risk is greater than that corresponding to the selected action value. The method requires the definition of three quantities, the action value, the number of days exposed above the action level, and the number of days employed. However, the 'number of days employed' does not seem an appropriate measure: continued employment that increases the number days employed but with little or no further exposure to vibration will lessen the responsibility of an employer for a former period of employment. A similar problem arises if the 'number of days employed' is replaced by the 'number 
of days exposed to hand-transmitted vibration': additional days of non-negligent exposure would paradoxically reduce responsibility for other days with negligent exposure.

The method means that the development of a disorder with continuous exposures (during a short period) will be more 'costly' than the same number of days of exposure over a longer period. This may have the effect of encouraging rotation of work so as to have days with little or no exposure, but if disorder is primarily dependent on the number of days exposed, a worker will receive, for the same disorder, only one-quarter of the compensation if his exposures are spread over a four times greater period of employment.

This method, unless refined further, seems to have many of the disadvantages of Method B and significant additional disadvantages.

\subsection{Method G: Negligent exposure based on the delay in the onset of the disorder or disability that would have been achieved with non-negligent exposures (i.e. 'the latent interval method')}

This method considers the benefit to a worker from the delay there would have been in the onset of the disorder or disability if the employer had not behaved negligently.

Reductions in vibration magnitude and exposure duration, and the adoption of other preventative measures are assumed to delay the onset of the symptoms and disability, reduce the rate of progression of disorder and, in general, reduce the severity of disorder reached at any time. With this method, the courts, guided by experts, will decide what percentage reductions in vibration magnitude and exposure duration, if any, would be expected of a non-negligent employer - it is not necessary to decide on the absolute vibration magnitudes or the absolute exposure durations. This reduction could arise from one of the methods described above (e.g. restricting exposures to $A(8)$ $=2.5 \mathrm{~ms}^{-2}$ r.m.s., or to $d_{10 \%}$ ). However, the method is most attractive and easiest to apply by comparing actual exposures with the lowest reasonably practical exposures.

This method has the considerable advantage that it allows the individual susceptibility of the employee to be taken into account. The 'latent interval' (i.e. the delay between first exposure to vibration and the first evidence of disorder) actually experienced by the worker as a result of negligent exposure is compared with the latent interval that would be expected if the worker had only experienced non-negligent exposures. The method must assume a relation between the latent period (in years) and the daily exposure duration and vibration magnitude (e.g. as defined in ISO 5349,2001 ). However, the method does not make other assumptions in current standards (e.g. the frequency weighting, similar weighting for all axes, and no effect of force or temperature) or that the methods correctly predict the onset of symptoms in an individual.

Extending the latent period before the onset of symptoms is helpful for both employees and employers. Future improvements in working conditions (including reduced vibration magnitudes and exposure durations) may be expected to further reduce the risks of vibration-induced white 
finger in the future and further lengthen the latent period. A worker may become sufficiently experienced to move to a supervisory position with less exposure to hand-transmitted vibration and, with a sufficient delay in the onset of symptoms a worker will retire before experiencing any problems.

As shown in equation (iv) above, ISO 5349 (2001) offers a relation between the daily exposure duration, $t$, to a frequency-weighted r.m.s. acceleration, $a_{\mathrm{hw}}$ and the years of exposure to handtransmitted vibration, $y_{10 \%}$, before $10 \%$ of persons are expected to have developed finger blanching:

$$
y_{10 \%}=\frac{30 \cdot \sqrt{T_{(8)}}}{a_{h w} \cdot \sqrt{t}}
$$

where $T_{(8)}$ is 8 hours.

For an individual worker with symptoms, the latent period is known - it is the time that elapsed between the date of first exposure to hand-transmitted vibration and the date when the first relevant symptoms became apparent. Consequently, the likely effects of reductions in vibration magnitude, $a_{\mathrm{hw}}$, and daily exposure duration, $t$, on the latent period can be calculated from the above equation. The effect of the above equation is that the latent interval doubles if the vibration magnitude, $a_{\mathrm{hw}}$, halves (i.e. reduced to 0.5 or $50 \%$ of its previous value) or if the exposure duration, $t$, reduces to a quarter (i.e. reduced to 0.25 or $25 \%$ of its former value). Alternatively, reducing both vibration magnitude and daily exposure duration will have a greater effect than reducing either the magnitude or the duration alone.

The calculations are based on the susceptibility of individual workers to vibration-induced white finger arising from their use of tools while in the employment of their employer: they are based on a worker's actual latent interval. The calculations therefore make no assumptions about the susceptibility of a worker relative to the average worker. The method assumes there are no changes to the circumstances of the individual that affect their susceptibility - any such changes (e.g. some other disorder that may directly or indirectly affect symptoms) should be taken into account when interpreting the calculated apportionment.

Having calculated the longer latent interval from the percentage reductions in vibration magnitude and duration that it is assumed the reasonable employer would have achieved, the worker might still be expected to have developed the onset of finger blanching within his anticipated working life with the employer.

The accuracy of this method is limited by doubts as to the range of disorders for which it is reasonable to predict the effects of reducing the vibration magnitude and the duration of daily exposure on the latent interval. Current standards only predict the latent interval for the onset of finger blanching - they do not give information how the vibration magnitude and the duration of daily exposure influence the rate of progression of vibration-induced white finger after the onset of 
finger blanching. They do not indicate how changing the vibration magnitude and the duration of daily exposure will affect the onset or progression of peripheral neurological symptoms (e.g. numbness or tingling) or other disorders. However, in the absence of information to the contrary, it seems reasonable to use the procedures as if they apply to the onset and progression of all effects of hand-transmitted vibration.

This method has the advantage that it can be used to predict how long an employee would have been able to remain in the same work with vibratory tools (and receive the same rate of pay) before developing vibration-induced white finger if the employer had not been negligent.

The method also has the advantage that it is not necessary to consider absolute magnitudes of vibration or absolute exposure durations. It is sufficient to decide on the percentage reduction, if any, in the vibration magnitude and daily duration of exposure which should have been achieved for example, it might be decided that the vibration magnitude could have been halved (by purchase of new tools or improved maintenance) or the daily exposure duration could have been halved (by sharing the work with another worker), or perhaps there could have been a combined reduction in both the magnitude and the duration of vibration exposure. It can be difficult to agree on actual vibration magnitudes and exposure durations but relatively easy to agree on means that would have reduced magnitudes and durations.

This method is appropriate up to the onset of first symptoms. After the onset of these symptoms, the actions of the employer should be orientated to the prevention of the progression of symptoms: this is better detected from monitoring the symptoms and any progression than from knowledge of the vibration magnitude and daily exposure duration.

When a worker has been exposed to hand-transmitted vibration with more than one employer, a similar calculation is required for all periods of employment before apportioning negligence to each employer. However, the consequence of the negligence of an individual employer is calculated from the benefit (delayed onset of symptoms) that could have been obtained from improvements during employment with that employer alone.

As with other methods, it would be complicated to make precise predictions when the exposure severity varies over the years. However, precise calculations are not appropriate and a reasonable 'broad brush' approach may lead to a reasonable conclusion.

A very attractive feature of this method is the avoidance of the calculation of the probability of whether the worker would have developed vibration-induced white finger with a different exposure: this eliminates the errors (e.g. those associated with the frequency weighting and the $A(8)$ timedependency) in current standards and the errors associated with the vast range of individual susceptibility among workers.

A principal assumption is that the worker provides a reasonably accurate estimate of the date of onset of symptoms of finger blanching. There are other limitations (see Table 6), but this method 
may be the most logical and most helpful method. It allows a comparison between what did happen and what would have happened if the employer had not acted negligently.

\section{TABLE 6 ABOUT HERE}

Where it is relevant, the method allows the calculation of the financial loss to workers of not being able to continue in employment without symptoms for as long as they would have continued if the exposures had been not been negligent. The benefits to the worker in respect of additional years without symptoms in their domestic and social lives may also be estimated. If a longer latent interval would have taken workers to the time in their working life when they would not have been using vibratory tools it can be assumed that the employer is fully responsible for their disabilities.

\subsection{Other methods}

An allowance for negligent exposure could be based on the balance of probability that the disorder could have been prevented. For an individual with vibration-induced white finger, a comparison may be made between the exposure that caused the condition and an exposure that would probably not have caused the condition. If an employer reduces the risk for the population of those exposed by more than $50 \%$ (e.g. the incidence is reduced from $20 \%$ to less than $10 \%$ ), on the balance of probability, it is more likely than not that any individual worker would not have developed the condition. If such a reduction was reasonable, then the employer who failed to institute the reduction might be assumed to be fully responsible for the disorder in an individual affected worker. Although ISO 5349 (2001) does not allow estimates of the incidence of finger blanching other than $10 \%$, this was possible with a former version of the standard (ISO 5349, 1986).

This method has the advantage over method $C$ in that the absolute probability of disorder need not be predicted: only the relative probability between the actual exposure and another exposure is required.

The method gives a binary outcome: either full responsibility or no responsibility falls on the employer, with potential unfairness to some workers and some employers. From the employer's point of view, if measures reduced the probability of injury by less than $50 \%$, the employer would be held fully responsible for the injury in all affected workers. The employer may point out that in all probability some of the workers would have benefited from the reductions. However, it is, of course, not possible to know which worker would have developed injury and which would not.

The method allows the selection of more than one criterion level of disorder: the probability of being able to prevent stage 2 disorders must be greater than being able to prevent stage 1 disorders. So, for a worker with stage 2 symptoms, if the courts were to decide there was a greater than $50 \%$ chance of stage 2 symptoms being prevented, but less than $50 \%$ chance of preventing stage 1 symptoms, the worker would be awarded compensation corresponding to the difference between stage 1 and stage 2 . 
This method, unless refined further, seems to have several disadvantages without significant advantages over some other methods.

\section{NEGLIGENCE OTHER THAN FAILURE TO REDUCE EXPOSURE}

Negligence is not only dependent on the vibration magnitude and exposure duration. It could be negligent if users of vibratory tools are not provided with information sufficient for them to understand the risks and the means of minimising the risks. Knowing the effects of vibration, and the possible influence of these effects on their occupation and leisure activities, some workers will choose to change job or change employer so as to lessen or eliminate exposure to handtransmitted vibration. Although many will hesitate or have difficulty in changing their job, over a period of time an understanding of the consequences of the risks may be sufficient to weigh in favour of other job alternatives as they arise, or as they can be created. The effect of warning some workers of the risks could therefore be the removal of the source of injury and the elimination of all risk to them. To be effective, a warning should be clear about the possible harmful effects and not seek to lessen the probability or potential seriousness of the condition.

It may be negligent not to take other preventative procedures (e.g. health surveillance) that can result in the condition being identified at an early stage. This can result in: (i) warning (with benefits as above), (ii) immediate elimination of further exposure, or (iii) reduction in exposures. These measures should prevent the progression of disease to an unacceptable level. What is unacceptable will vary according to the social, political, and economic situation, but it might be the level of disease that is a threat to continued work with vibration, or a threat to alternative employment without vibration, or a threat to the enjoyment of leisure activities.

Some preventative procedures (including health surveillance and vibration monitoring) can draw attention to the risks and result in reductions in vibration magnitude, exposure duration, grip force, etc. that may reduce the risks. Other preventative procedures (e.g. job rotation, tool maintenance, and limits to exposure duration) should prevent the occurrence of occasional extreme exposures that may be associated with exceptional risks.

In summary, the prudent employer will seek to reduce risks by warning, health surveillance, instruction on the proper use of tools, selection of tools with minimum vibration, and restricting the maximum duration of exposure to vibration in any day. In addition, the use of gloves, control of the environment and similar matters may sometimes help to reduce the probability of disorders developing or minimise their severity.

\section{DISCUSSION}

Any apportionment between negligent and non-negligent exposures should recognise that the health effects of hand-transmitted vibration depend on the total exposure to vibration and not merely the vibration magnitude and the daily duration of exposure. Using daily exposure action 
values as a basis for distinguishing between negligent and non-negligent exposures is fundamentally flawed: the risk depends on the years of exposure and not merely the equivalent daily exposure - lifetime exposures at the current EU daily exposure action value can carry significant risks of injury. This means that an employer cannot argue that a vibration exposure is not negligent because it has been reduced to below the daily exposure action level: conditions below the action level can present significant risks and so warning, training, education and health surveillance and other preventative measures (including minimisation of vibration exposure) are required for exposures below the action level.

To define negligent and non-negligent exposures by a fixed value disregards whether it is reasonably practical to achieve this exposure or, indeed, whether it is reasonably practical to achieve lower exposures and, therefore, even lower risks. If negligence is to be related to vibration magnitudes and exposure durations it would seem more reasonable to consider the exposures that can reasonably be achieved by employers.

\subsection{Comparison of methods}

Method A (quantifying negligence based on severity of disease) may be the simplest. This method is not dependent on estimates of the vibration exposure and takes into account the individual susceptibility of the worker. Nevertheless, some limitations make it insufficient: it does not prevent disorders and will not always encourage the minimisation of risk. Another method is required to apportion for the negligence in allowing the onset of disorder; Method A can be used to account for the negligence in allowing the disorder to progress.

Method D (combining a daily exposure action value with conditions expected to produce $10 \%$ finger blanching) overcomes some of the limitations of using a daily exposure action value alone to define negligent exposure. This method might be considered to define the conditions above which a reasonable employer would definitively need to provide warning, education, training, health surveillance, and other preventative measures. However, it is only possible to predict the exposure causing $10 \%$ finger blanching by assuming for how many years in total a worker will be exposed to hand-transmitted vibration. For a young worker this will be many years and the corresponding daily exposure very low (see Figure 1). As with other methods based on fixed exposures, it takes no account of what is reasonably achievable (it may require more or less than can be achieved) and it does not take into account individual susceptibility.

Method E (negligence directly based on a comparison between actual exposures and reasonably achievable vibration magnitudes and daily exposure durations) is logical and reasonable but difficult to apply in practice. It requires the definition of a dose measure to make the comparison between the two exposures and a decision on the absolute magnitudes of both the actual exposure durations and actual vibration magnitudes and the reasonably achievable exposure durations and 
magnitudes. The method does not take into account individual susceptibility and requires appreciably more assumptions than Method G.

Method $G$ (negligence based on the delay in the onset of the disorder that would have been achieved with non-negligent exposures; i.e. the 'latent interval method') overcomes the limitations of several other methods. In particular it takes account of individual susceptibility to the effects of hand-transmitted vibration as well as what is reasonably achievable. The method only requires the courts to decide on the percentage reduction, if any, in the vibration magnitudes and exposure durations that should have been achieved. The wide distribution of vibration magnitudes on similar tools and the possibility for job rotation means that unless tools have been appropriately selected and the exposure durations well-controlled, reductions in vibration magnitudes and exposure durations will be considered to have been possible. A two-fold reduction in vibration magnitude corresponds to a doubling of the latent interval, which may be sufficient to prevent the development of symptoms in many workers before their retirement. In which case, the employer becomes wholly responsible for the development of the condition. The method is based on the onset of clearly demarcated finger blanching, but it cuurently seems reasonable to use the same method for other symptoms.

The most appropriate and accurate methods will be those that take into account the practicality of reducing the exposure of the workers (i.e. Methods $E$ and $G$ ) and the susceptibility of the workers (i.e. Methods $A$ and $G$ ). On this basis, method $G$ (the latency method) seems to be the most useful means for assessing any negligence of employers.

Exposures that took place before an employer could have known about the risks and taken steps to reduce the risks will not be negligent exposures. Similarly, an employer cannot be considered responsible for exposures that took place while an employee was working for another employer. However, the responsible employer should recognise that previous exposures to hand-transmitted vibration increase the probability of a worker developing the hand-arm vibration syndrome. The employer may therefore be expected to take greater than average care of workers who have a long history of exposure to hand-transmitted vibration.

\section{APPORTIONMENT FOR RESIDUAL RISKS USING METHOD G (THE LATENCY METHOD)}

The latency method is illustrated below for a worker who is assumed to have been born in 1960, commenced work with exposures to hand-transmitted vibration at the age of 20 in 1980 and developed the onset of finger blanching at the age of 40 in 2000 . His latent period for the development of the symptoms that were present in 2000 was therefore 20 years.

Assuming that his exposures to hand-transmitted vibration were more or less uniform, it is possible to estimate the years of exposure before this worker would have developed the same symptoms 
(i.e. the vibration-induced symptoms that were present in 2000) if the vibration magnitudes or the daily exposure durations had been reduced.

A $50 \%$ increase in the latent period would have taken the worker to the age of 50 years, before the onset of symptoms in 2010. A doubling of the latent period would have taken him to the age of 60 years, in 2020.

According to ISO 5349 (2001) the latent interval, $y_{10 \%}$, for $10 \%$ finger blanching is related to the vibration magnitude, $a_{\mathrm{hw}}$, and daily exposure duration, $t$, as follows:

$$
y_{10 \%}=\frac{30 \cdot \sqrt{T_{(8)}}}{a_{h w} \cdot \sqrt{t}}
$$

where $T_{(8)}$ is 8 hours.

The latent interval, $y_{10 \%}$, doubles if the vibration magnitude, $a_{\mathrm{hw}}$, is halved or if the daily exposure duration, $t$, is reduced to a quarter. Alternatively some combination of reducing vibration magnitude and daily exposure duration will have a greater effect than reducing either the vibration magnitude or the exposure duration alone. The effects of reducing the vibration magnitudes and daily exposure duration for this example worker are summarised in Table 7 . The predicted effects of various combinations of reductions in vibration magnitude and exposure duration on his latency and age of onset of finger blanching are shown in Tables 8 and 9, respectively.

\section{TABLES 7, 8 AND 9 ABOUT HERE}

If the vibration magnitude had been reduced to about $50 \%$ of the actual magnitude or if the daily duration of exposure to hand-transmitted vibration had been reduced to about $25 \%$ of the actual duration, an extension of the latent interval to the age of 60 years (in 2020) would have been expected, according to ISO 5349 (2001). Alternatively, the onset of the symptoms could have been delayed to this extent with some equivalent combined reduction in both the vibration magnitude and exposure duration (see Tables 8 and 9).

For this worker, an extension of the latent interval to the age of 65 years (in 2025) would have been expected, according to ISO 5349, if the vibration magnitude had been reduced to about $44 \%$ of the actual magnitude, or if the daily duration of exposure to hand-transmitted vibration had been reduced to about $20 \%$ of the actual duration, or there had been some equivalent combined reduction in both the vibration magnitude and exposure duration (e.g., a $30 \%$ reduction in vibration magnitude and a $60 \%$ reduction in exposure duration - see Table 9).

If the worker did not share his work equally with one other man in a two-man gang, the introduction of a work rotation scheme so that he shared his work equally with one member of his gang (reduction to $50 \%$ of former duration) would have halved his duration of daily exposure and increased his latent period by about $40 \%$. If the worker shared his work equally with one man in a 
two-man gang, the introduction of 3-man gangs would have reduced his daily vibration exposure by $33 \%$ and increased the latent interval by about $22 \%$.

The calculations use the susceptibility of this worker to vibration-induced injury arising from his use of tools as provided by his employer. The calculations therefore make no assumptions about his susceptibility relative to the average worker. The calculations do not assume that current standards can accurately predict the development of vibration-induced injury from the tools he used (e.g. it is not necessary to assume that the effect of vibration frequency on the development of vibrationinduced injury is accurately predicted by the standards). A principal assumption is that the worker first developed symptoms as a result of exposure to hand-transmitted vibration after about 20 years of tool use and that the latency for the development of symptoms is inversely proportional to vibration magnitude and proportional the square root of daily exposure duration (as assumed in ISO 5349, 1986 and in ISO 5349, 2001). While future epidemiological studies may find these assumptions to be non-optimum, they are the relationships agreed by international consensus at this time.

\section{CONCLUSIONS}

Daily exposure action values are not suitable for distinguishing between negligent and nonnegligent exposures because the risks of disorder from hand-transmitted vibration depend on the years of exposure, not merely the equivalent daily exposure. Furthermore, daily exposure action values take no account of individual susceptibility or the practicality of reducing vibration exposures.

The consequences of negligence may be quantified in terms of the delay in the onset of disorder that would have been achieved if the exposures had been the minimum reasonably achievable in the circumstances. This only requires decisions on the percentage reductions in vibration magnitude and exposure duration, if any, that would have been achieved by the reasonable employer. It seems to be a fair and reasonable method for both employers and employees. It also provides information needed to calculate the consequences of negligence on the worker - the period of their life with disease as a result of the negligence and, if appropriate, the period for which their employment is jeopardised as a result of the onset a disorder due to the negligence of their employer.

Negligence of employers may not be confined to failure to delay the onset of disorders by reasonably achievable reductions in vibration magnitudes and exposure durations. Employers should provide workers with an understanding of the risks and their cause (i.e. warning), the means of preventing the risks (e.g. training), and prevent the progression of disorders by implementing suitable health surveillance. 


\section{ACKNOWLEDGEMENTS}

This research was supported by the European Commission under the Quality of Life and Management of Living Resources programme, project no. QLK4-2002-02650 (VIBRISKS).

\section{REFERENCES}

1. Brammer AJ, Taylor W, Lundborg G (1987) Sensorineural stages of the hand-arm vibration syndrome. Scand J Work Environ Health 13: 279-283

2. British Standards Institution (1987) Measurement and evaluation of human exposure to vibration transmitted to the hand, British Standard, London: BSI 1987:6842

3. Gemne G, Pyykkö I, Taylor W, Pelmear PL (1987) The Stockholm Workshop scale for the classification of cold-induced Raynaud's phenomenon in the hand-arm vibration syndrome (revision of the Taylor-Pelmear scale). Scand J Work Environ Health 13: 275-278

4. Griffin MJ (1990) Handbook of human vibration. Academic Press, London

5. Griffin MJ (1994) Foundations of hand-transmitted vibration standards. Nagoya Journal of Medical Science, 57, (Supplement), 147-164.

6. Griffin MJ (1997) Measurement, evaluation, and assessment of occupational exposures to hand-transmitted vibration. Occup Environ Health 54: 73-89.

7. Griffin MJ (2004) Minimum health and safety requirements for workers exposed to handtransmitted vibration and whole-body vibration in the European Union; a review. Occupational and Environmental Medicine; 61, 387-397.

8. Griffin MJ (2007) Measurement, evaluation, and assessment of peripheral neurological disorders caused by hand-transmitted vibration. Presented at $2^{\text {nd }}$ International Workshop of the diagnosis of disorders caused by hand-transmitted vibration; Gothenburg, $6-7^{\text {th }}$ e September 2006.

9. Griffin MJ, Bovenzi M (2002) The diagnosis of disorders caused by hand-transmitted vibration: Southampton Workshop 2000. International Archives of Occupational and Environmental Health, $75,(1-2), 1-5$. 
10. International Organization for Standardization (1986) Mechanical vibration - Guidelines for the measurement and the assessment of human exposure to hand-transmitted vibration. ISO 5349. ISO, Geneva

11. International Organization for Standardization (2001) Mechanical vibration - measurement and evaluation of human exposure to hand-transmitted vibration - Part 1: General requirements. Geneva: ISO, 2001: 5349-1 (E).

12. The European Parliament and the Council of the European Union (2002) On the minimum health and safety requirements regarding the exposure of workers to the risks arising from physical agents (vibration). Directive 2002/44/EC; Official Journal of the European Communities, 6th July 2002; L177/13-19. 
Table 1 Limitations and consequences of Method $A$ for defining negligence: negligence based on severity of disease (i.e. reaching stage $N$ ).

\begin{tabular}{|l|l|}
\hline A.1 & $\begin{array}{l}\text { The staging systems (and indicators of disease in general) do not provide } \\
\text { good predictions of the degree of disability in an individual. }\end{array}$ \\
\hline A.2 & $\begin{array}{l}\text { Employers responsible for previous exposures that contributed to damage } \\
\text { within the worker prior to the onset of stage } N \text { symptoms would carry no } \\
\text { responsibility. This has the effect of attaching greater weight to later periods of } \\
\text { exposure. }\end{array}$ \\
\hline A.3 & $\begin{array}{l}\text { The method is dependent on identifying that stage } N \text { is reached. However, } \\
\text { because the disease is insidious, workers have difficulty identifying the } \\
\text { progression of symptoms. }\end{array}$ \\
\hline A.4 & $\begin{array}{l}\text { The current staging systems are not well defined or suitable for this purpose. } \\
\text { A.5 }\end{array}$ \\
$\begin{array}{l}\text { If the threshold level is set to stage 1 there will be no compensation for the } \\
\text { onset of the first symptoms (e.g. blanching of fingertips, numbness or tingling) } \\
\text { which are associated with some disability and may be considered worthy of } \\
\text { compensation. }\end{array}$ \\
\hline A.6 & $\begin{array}{l}\text { This method would result in workers being moved from vibration work on } \\
\text { reaching stage } N \text {. Loss of income due to change of work would require } \\
\text { compensation. }\end{array}$ \\
\hline A.7 & $\begin{array}{l}\text { The method only indirectly encourages a reduction in the severity of vibration } \\
\text { exposures: employers could expose workers to unnecessary vibration until } \\
\text { symptoms develop. }\end{array}$ \\
\hline A.8 & The method assumes it is not negligent to allow the onset of disorder. \\
\hline
\end{tabular}


Table 2 Limitations and consequences of Method B for defining negligence: negligent based on a daily exposure action value.

\begin{tabular}{|c|c|}
\hline B.1 & $\begin{array}{l}\text { Daily exposure action values are not directly related to harm, symptoms or } \\
\text { disability - partly because they take no account of years of exposure or } \\
\text { individual susceptibility. }\end{array}$ \\
\hline B.2 & $\begin{array}{l}\text { The EU exposure action value }\left(A(8)=2.5 \mathrm{~ms}^{-2} \text { r.m.s.) is associated with }\right. \\
\text { significant risks of injury over a working life. Employees should not be exposed } \\
\text { to a risk that is known, or ought to be known, by an employer without being } \\
\text { supplied with information and warning so as to have a full understanding of the } \\
\text { risks. They should understand the full nature of the possible disorders and the } \\
\text { predicted probability of developing a disorder. }\end{array}$ \\
\hline B.3 & $\begin{array}{l}\text { Within the EU it is not sufficient to reduce exposures to the exposure action } \\
\text { value }\left(A(8)=2.5 \mathrm{~ms}^{-2} \text { r.m.s.). The Directive of the Council of the European }\right. \\
\text { Communities states: "Taking account of technical progress and of the } \\
\text { availability of measures to control the risk at source, the risks arising from } \\
\text { exposure to mechanical vibration shall be eliminated at their source or } \\
\text { reduced to a minimum". }\end{array}$ \\
\hline B.4 & $\begin{array}{l}\text { An } A(8)=1.0 \mathrm{~ms}^{-2} \text { r.m.s. action level gives a more reasonable protection to } \\
\text { employees over a typical working life, but may give 'excessive protection' with } \\
\text { some exposures limited to a few years - which would result in no claims for } \\
\text { injury but increase the costs of production. }\end{array}$ \\
\hline B.5 & $\begin{array}{l}\text { It may not be reasonably practical for an employer to reduce exposures to a } \\
\text { specific daily exposure action value. }\end{array}$ \\
\hline B.6 & $\begin{array}{l}\text { The use of estimated vibration exposures to define 'non-negligent exposure', } \\
\text { assumes that reduction in the magnitude or duration of vibration is the only } \\
\text { reasonable preventative measure. There may be other means of prevention } \\
\text { before the onset of symptoms. }\end{array}$ \\
\hline B.7 & $\begin{array}{l}\text { After the onset of symptoms, actions should be orientated to the prevention of } \\
\text { the progression of symptoms: this is better detected from monitoring the } \\
\text { symptoms and their progression than from knowledge of the vibration } \\
\text { magnitude and daily exposure duration. }\end{array}$ \\
\hline B.8 & $\begin{array}{l}\text { As it becomes increasingly easy to detect and diagnose disorders arising from } \\
\text { hand-transmitted vibration, more workers will claim compensation for lesser } \\
\text { symptoms caused by exposures in excess of the daily exposure action value. } \\
\text { Meanwhile, others with more severe disorders arising from exposures below } \\
\text { the daily exposure action value would be uncompensated. }\end{array}$ \\
\hline B.9 & $\begin{array}{l}\text { The method ignores advice that the possibility of a risk of injury should be } \\
\text { investigated for specific tools and processes known to cause injury and also } \\
\text { for regular prolonged use of any high vibration tool or machine. }\end{array}$ \\
\hline B.10 & $\begin{array}{l}\text { The method does not take into account individual variability in the } \\
\text { development and progression of disorders caused by hand-transmitted } \\
\text { vibration. }\end{array}$ \\
\hline
\end{tabular}


Table 3 Limitations and consequences of Method $C$ for defining negligence: negligence based on the dose of vibration expected to produce $10 \%$ finger blanching.

\begin{tabular}{|l|l|}
\hline C.1 & $\begin{array}{l}\text { Current methods of predicting the probability of developing injury from hand- } \\
\text { transmitted vibration are not sufficiently accurate means of predicting harm, } \\
\text { symptoms, or disability - partly because they take no account of individual } \\
\text { susceptibility. }\end{array}$ \\
\hline C.2 & $\begin{array}{l}\text { The method assumes that it is acceptable for } 1 \text { in } 10 \text { workers to develop } \\
\text { symptoms. }\end{array}$ \\
\hline C.3 & $\begin{array}{l}\text { A series of employers could expose a worker to a dose just short of the } \\
\text { negligent dose. Each period may only last a few years yet the cumulative } \\
\text { exposure of the worker could be highly likely to result in finger blanching. If this } \\
\text { method is based on the accumulated lifetime dose received in all work, it } \\
\text { would require each employer to calculate a lifetime dose before employment } \\
\text { from information supplied by a prospective employee. }\end{array}$ \\
\hline C.4 & $\begin{array}{l}\text { The method expects greater precautions with more years of exposure and so } \\
\text { apportions greater responsibility the longer an exposure continues. }\end{array}$ \\
\hline C.5 & $\begin{array}{l}\text { The method only indirectly encourages a reduction in vibration magnitudes } \\
\text { and exposure durations. Employers could expose workers to unnecessary } \\
\text { vibration until the negligent dose is reached. }\end{array}$ \\
\hline & \begin{tabular}{l} 
Also B6, B7, B9, and B10. \\
\hline
\end{tabular}
\end{tabular}


Table 4 Limitations and consequences of Method $D$ for apportioning defining negligence: negligent exposure based on limiting exposures to a daily exposure action value and to conditions not expected to produce $10 \%$ finger blanching.

\begin{tabular}{|l|l|}
\hline D.1 & $\begin{array}{l}\text { Some tools are more likely to cause a } 10 \% \text { incidence of symptoms and other } \\
\text { less likely to cause } 10 \% \text { incidence of symptoms than predicted. This method } \\
\text { takes no account of such differences in determining negligence. In the } \\
\text { extreme, deliberate exposure to a known high risk may not be negligent by this } \\
\text { method. }\end{array}$ \\
\hline D.2 & $\begin{array}{l}\text { With more than one employer, the method is complex. For each period of } \\
\text { employment the exposure beneath the daily exposure action value, or below } \\
\text { the dose required for } 10 \% \text { blanching, would be discounted before an } \\
\text { apportionment between periods is applied. }\end{array}$ \\
\hline Also B1, B6, B7, B9, B10, C1, C2, C3, C4, C6, C5 \\
\hline
\end{tabular}


Table 5 Limitations of Method $\mathrm{E}$ for defining negligence: negligent based on reasonably achievable vibration magnitudes and daily exposure durations.

\begin{tabular}{|l|l|}
\hline E.1 & $\begin{array}{l}\text { It may be difficult to determine the reasonably achievable vibration exposures } \\
\text { without the assistance of experts. Even if suitable experts agree on absolute } \\
\text { vibration magnitudes they will often be unable to agree on absolute exposure } \\
\text { durations, since there is often differing evidence from workers and employers. }\end{array}$ \\
\hline E.2 & $\begin{array}{l}\text { The consequences of negligence may be difficult to determine when there has } \\
\text { been more than one employer. The lowest reasonably practicable exposure } \\
\text { would need to be discounted before an apportionment between periods is } \\
\text { applied. }\end{array}$ \\
\hline & Also B6, B7, B10 \\
\hline
\end{tabular}


Table 6 Limitations of Method $G$ for defining negligence: negligence based on the delay in the onset of the disorder that would have been achieved with non-negligent exposures (i.e. 'the latent interval method').

\begin{tabular}{|l|l|}
\hline G.1 & $\begin{array}{l}\text { The percentage reduction in vibration exposure (magnitude and daily duration) } \\
\text { which the worker should have benefited from must be decided. }\end{array}$ \\
\hline G.2 & $\begin{array}{l}\text { It is assumed that the delay in the onset of symptoms is inversely proportional to } \\
\text { the vibration magnitude and the square-root of the daily exposure duration (as in } \\
\text { current standards). }\end{array}$ \\
\hline G.3 & $\begin{array}{l}\text { It is assumed that the worker can provide a reasonable estimate of the date of } \\
\text { onset of symptoms. }\end{array}$ \\
\hline & Also B6, B7 \\
\hline
\end{tabular}


Table 7 Latency expectancy tables for a worker showing the anticipated effect of percentage reductions in tool acceleration magnitudes and daily durations of vibration exposure. Table assumes that the worker was born in 1960, commenced exposure to hand-transmitted vibration in 1980, first developed symptoms of finger blanching in 2000 at the age of 40 years after a latent period of 20 years, and that his exposure to vibration was uniform in severity over all actual and possible exposure periods.

\begin{tabular}{|c|c|c|c|c|c|c|c|}
\hline \multicolumn{4}{|c|}{ Effect of varying acceleration magnitude } & \multicolumn{4}{|c|}{ Effect of varying daily exposure duration } \\
\hline $\begin{array}{l}\text { Acceleration } \\
\text { (\% of actual) }\end{array}$ & $\begin{array}{l}\text { Latent } \\
\text { Interval } \\
\text { (years) }\end{array}$ & $\begin{array}{c}\text { Age } \\
\text { (years) }\end{array}$ & Year & $\begin{array}{c}\text { Daily } \\
\text { exposure } \\
\text { duration } \\
\text { (\% of actual) }\end{array}$ & $\begin{array}{l}\text { Latent } \\
\text { interval } \\
\text { (years) }\end{array}$ & $\begin{array}{c}\text { Age } \\
\text { (years) }\end{array}$ & Year \\
\hline 100.0 & 20.0 & 40.0 & 2000 & 100.0 & 20.0 & 40.0 & 2000 \\
\hline 95.0 & 21.1 & 41.1 & 2001 & 95.0 & 20.5 & 40.5 & 2001 \\
\hline 90.0 & 22.2 & 42.2 & 2002 & 90.0 & 21.1 & 41.1 & 2001 \\
\hline 85.0 & 23.5 & 43.5 & 2004 & 85.0 & 21.7 & 41.7 & 2002 \\
\hline 80.0 & 25.0 & 45.0 & 2005 & 80.0 & 22.4 & 42.4 & 2002 \\
\hline 75.0 & 26.7 & 46.7 & 2007 & 75.0 & 23.1 & 43.1 & 2003 \\
\hline 70.0 & 28.6 & 48.6 & 2009 & 70.0 & 23.9 & 43.9 & 2004 \\
\hline 65.0 & 30.8 & 50.8 & 2011 & 65.0 & 24.8 & 44.8 & 2005 \\
\hline 60.0 & 33.3 & 53.3 & 2013 & 60.0 & 25.8 & 45.8 & 2006 \\
\hline 55.0 & 36.4 & 56.4 & 2016 & 55.0 & 27.0 & 47.0 & 2007 \\
\hline 50.0 & 40.0 & 60.0 & 2020 & 50.0 & 28.3 & 48.3 & 2008 \\
\hline 45.0 & 44.4 & 64.4 & 2024 & 45.0 & 29.8 & 49.8 & 2010 \\
\hline 40.0 & 50.0 & 70.0 & 2030 & 40.0 & 31.6 & 51.6 & 2012 \\
\hline 35.0 & 57.1 & 77.1 & 2037 & 35.0 & 33.8 & 53.8 & 2014 \\
\hline 30.0 & 66.7 & 86.7 & 2047 & 30.0 & 36.5 & 56.5 & 2017 \\
\hline 25.0 & 80.0 & 100.0 & 2060 & 25.0 & 40.0 & 60.0 & 2020 \\
\hline 20.0 & - & - & - & 20.0 & 44.7 & 64.7 & 2025 \\
\hline 15.0 & - & - & - & 15.0 & 51.6 & 71.6 & 2032 \\
\hline 10.0 & - & - & - & 10.0 & 63.2 & 83.2 & 2043 \\
\hline
\end{tabular}


Table 8 Latency expectancy table for a worker showing the anticipated effect of combined percentage reductions in tool acceleration magnitudes and daily durations of vibration exposure on latency. Table assumes that the worker was born in 1960, commenced exposure to handtransmitted vibration in 1980, first developed symptoms of finger blanching in 2000 at the age of 40 years after a latent period of 20 years, and that his exposure to vibration was uniform in severity over all actual and possible exposure periods.

Predicted latency (years)

\begin{tabular}{|c|c|c|c|c|c|c|c|c|c|c|}
\hline & \multicolumn{10}{|c|}{ Daily exposure (\% of actual) } \\
\hline $\begin{array}{c}\text { Acceleration } \\
\text { (\% of actual) }\end{array}$ & 100 & 90 & 80 & 70 & 60 & 50 & 40 & 30 & 20 & 10 \\
\hline 100.0 & 20.0 & 21.1 & 22.4 & 23.9 & 25.8 & 28.3 & 31.6 & 36.5 & 44.7 & 63.2 \\
\hline 90.0 & 22.2 & 23.4 & 24.8 & 26.6 & 28.7 & 31.4 & 35.1 & 40.6 & 49.7 & - \\
\hline 80.0 & 25.0 & 26.4 & 28.0 & 29.9 & 32.3 & 35.4 & 39.5 & 45.6 & - & - \\
\hline 70.0 & 28.6 & 30.1 & 31.9 & 34.1 & 36.9 & 40.4 & 45.2 & - & - & - \\
\hline 60.0 & 33.3 & 35.1 & 37.3 & 39.8 & 43.0 & 47.1 & - & - & - & - \\
\hline 50.0 & 40.0 & 42.2 & 44.7 & 47.8 & - & - & - & - & - & - \\
\hline 40.0 & 50.0 & - & - & - & - & - & - & - & - & - \\
\hline 30.0 & 66.7 & - & - & - & - & - & - & - & - & - \\
\hline 20.0 & 100.0 & - & - & - & - & - & - & - & - & - \\
\hline 10.0 & - & - & - & - & - & - & - & - & - & - \\
\hline
\end{tabular}


Table 9 Latency expectancy table for a worker showing the anticipated effect of combined percentage reductions in tool acceleration magnitudes and daily durations of vibration exposure on expected age at onset of symptoms. Table assumes that the worker was born in 1960, commenced exposure to hand-transmitted vibration in 1980, first developed symptoms of finger blanching in 2000 at the age of 40 years after a latent period of 20 years, and that his exposure to vibration was uniform in severity over all actual and possible exposure periods.

Predicted age (years)
\begin{tabular}{|c|c|c|c|c|c|c|c|c|c|c|}
\hline & \multicolumn{10}{|c|}{ Daily exposure (\% of actual) } \\
\hline $\begin{array}{l}\text { Acceleration } \\
\text { (\% of actual) }\end{array}$ & 100 & 90 & 80 & 70 & 60 & 50 & 40 & 30 & 20 & 10 \\
\hline 100.0 & 40.0 & 41.1 & 42.4 & 43.9 & 45.8 & 48.3 & 51.6 & 56.5 & 64.7 & 83.2 \\
\hline 90.0 & 42.2 & 43.4 & 44.8 & 46.6 & 48.7 & 51.4 & 55.1 & 60.6 & 69.7 & 90.3 \\
\hline 80.0 & 45.0 & 46.4 & 48.0 & 49.9 & 52.3 & 55.4 & 59.5 & 65.6 & 75.9 & 99.1 \\
\hline 70.0 & 48.6 & 50.1 & 51.9 & 54.1 & 56.9 & 60.4 & 65.2 & 72.2 & 83.9 & - \\
\hline 60.0 & 53.3 & 55.1 & 57.3 & 59.8 & 63.0 & 67.1 & 72.7 & 80.9 & 94.5 & - \\
\hline 50.0 & 60.0 & 62.2 & 64.7 & 67.8 & 71.6 & 76.6 & 83.2 & 93.0 & - & - \\
\hline 40.0 & 70.0 & 72.7 & 75.9 & 79.8 & 84.5 & 90.7 & 99.1 & - & - & - \\
\hline 30.0 & 86.7 & 90.3 & 94.5 & 99.7 & - & - & - & - & - & - \\
\hline 20.0 & - & - & - & - & - & - & - & - & - & - \\
\hline 10.0 & - & - & - & - & - & - & - & - & - & - \\
\hline
\end{tabular}




\section{Figure captions}

Figure 1 Limiting exposures for Method B (EU daily exposure action value of $2.5 \mathrm{~ms}^{-2}$ r.m.s.), Method C (exposures corresponding to $10 \%$ prevalence of vibration-induced white finger according to ISO 5349, 2001), and Method D (combination of Methods B and C - shown in grey). 


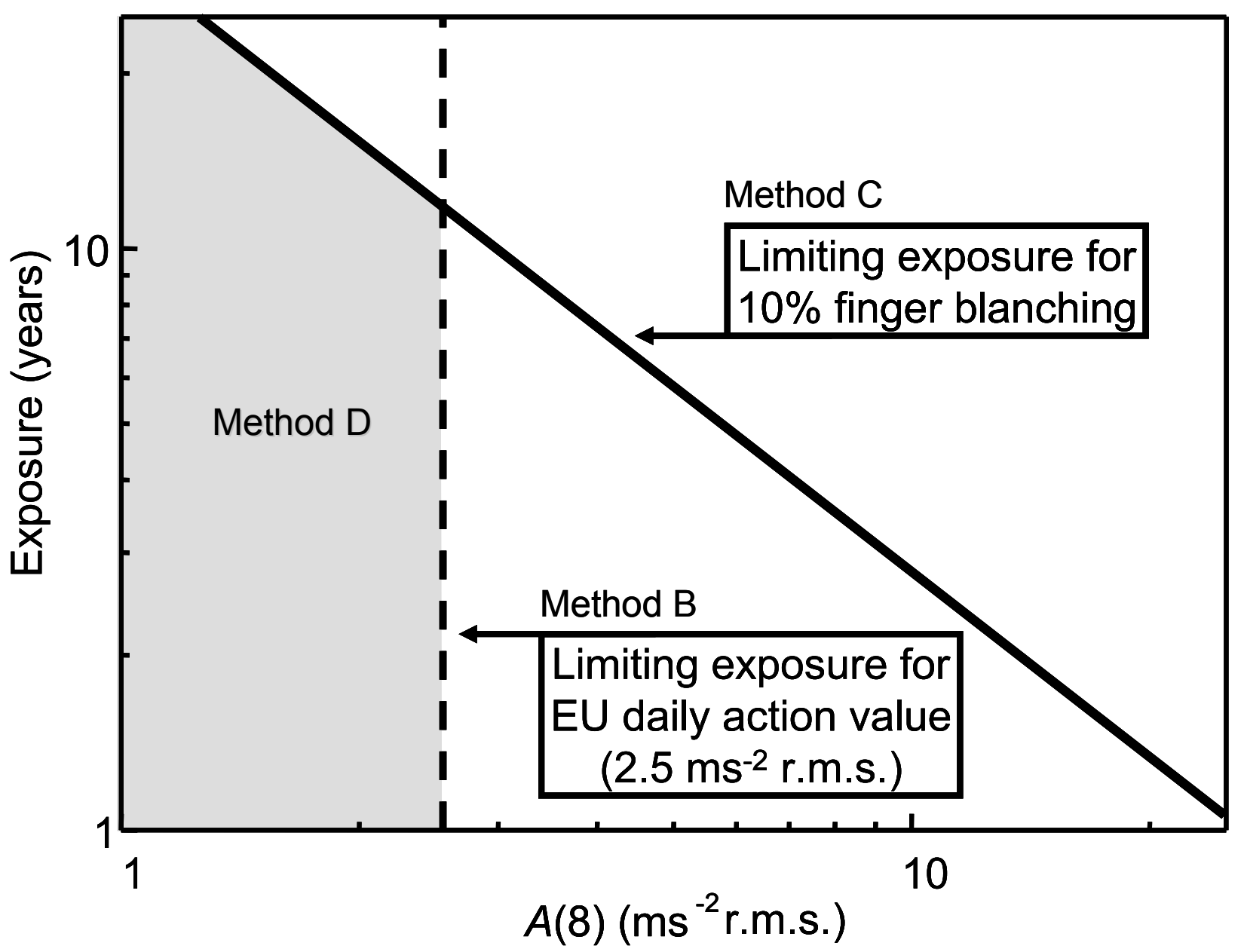

Figure 1 Limiting exposures for Method B (EU daily exposure action value of $2.5 \mathrm{~ms}^{-2}$ r.m.s.), Method C (exposures corresponding to $10 \%$ prevalence of vibration-induced white finger according to ISO 5349, 2001), and Method D (combination of Methods B and C - shown in grey). 